\title{
BMJ Open Psychological factors for the onset of depression: a meta-analysis of prospective studies
}

\author{
Zhongfang Fu, ${ }^{1}$ Marlies Brouwer (D) , ${ }^{1}$ Mitzy Kennis, ${ }^{2}$ Alishia Williams, ${ }^{3}$ \\ Pim Cuijpers (D) , ${ }^{4}$ Claudi Bockting ${ }^{1,5}$
}

To cite: Fu Z, Brouwer M, Kennis M, et al. Psychological factors for the onset of depression: a meta-analysis of prospective studies. BMJ Open 2021;11:e050129. doi:10.1136/ bmjopen-2021-050129

- Prepublication history and additional supplemental material for this paper are available online. To view these files, please visit the journal online (http://dx.doi.org/10.1136/ bmjopen-2021-050129)

Received 11 February 2021 Accepted 14 July 2021

Check for updates

(c) Author(s) (or their employer(s)) 2021. Re-use permitted under CC BY-NC. No commercial re-use. See rights and permissions. Published by BMJ.

${ }^{1}$ Department of Psychiatry, Amsterdam UMC, Location AMC, Amsterdam, The Netherlands ${ }^{2}$ ARQ National Psychotrauma Centre, ARQ centre of Expertise for the Impact of Disasters and Crises, Diemen, The Netherlands ${ }^{3}$ Department of Psychology, University of New South Wales, Sydney, New South Wales, Australia

${ }^{4}$ Department of Clinical Psychology, Vrije Universiteit Amsterdam, Amsterdam, The Netherlands

${ }^{5}$ Centre for Urban Mental Health, University of Amsterdam,

Amsterdam, The Netherlands

Correspondence to

Claudi Bockting;

c.l.bockting@amsterdamumc.nl

\section{ABSTRACT}

Objectives A comprehensive overview of the evidence for factors derived from leading psychological theories of the onset of major depressive disorder (MDD) that underpin psychological interventions is scarce . We aimed to systematically investigate the prospective evidence for factors derived from the behavioural, cognitive, diathesisstress, psychodynamic and personality-based theories for the first onset of MDD.

Design Systematic review and meta-analysis.

Methods Databases PubMed, PsycINFO, Cochrane and Embase and published articles were systematically searched from inception up to August 2019. Prospective, Iongitudinal studies that investigated theory-derived factors before the first onset of MDD, established by a clinical interview, were included. Screening, selection and data extraction of articles were conducted by two screeners. The Grading of Recommendations Assessment, Development and Evaluation criteria were used to estimate level of confidence and risk of bias. Meta-analysis was conducted using random-effects models and mixed-method subgroup analyses.

Primary and secondary outcome measures Effect size of a factor predicting the onset of MDD (OR, risk ratio or $\mathrm{HR})$.

Results From 42133 original records published to August 2019, 26 studies met the inclusion criteria. Data were only available for the cognitive $(n=6585)$ and personality-based $(n=14394)$ theories. Factors derived from cognitive theories and personality-based theories were related to increased odds of MDD onset (pooled OR=2.12, 95\% Cl: 1.12 to 4.00; pooled $\mathrm{OR}=2.43,95 \% \mathrm{Cl}: 1.41$ to 4.19 ). Publication bias and considerable heterogeneity were observed.

Conclusion There is some evidence that factors derived from cognitive and personality-based theories indeed predict the onset of MDD (ie, dysfunctional attitudes and negative emotionality). There were no studies that prospectively studied factors derived from psychodynamic theories and not enough studies to examine the robust evidence for behavioural and diathesis-stress theories. Overall, the prospective evidence for psychological factors of MDD is limited, and more research on the leading psychological theories is needed.

PROSPERO registration number CRD42017073975.

Major depressive disorder (MDD) is a prevalent and highly disabling mental health disorder that has been identified as one of

\section{Strengths and limitations of this study}

- This meta-analysis investigated the prospective evidence for factors derived from five psychological theories of major depressive disorder (MDD): behavioural, cognitive, psychodynamic, personalitybased and diathesis-stress.

- Prospective, longitudinal studies that investigated theory-derived factors before the first onset of MDD, as established by a clinical interview, were included.

- This meta-analysis was an extensive broad review that included prospective, longitudinal studies that assessed the psychological factors before the first onset of MDD, and where MDD was established through clinical interviews.

- The limited number of eligible prospective studies with theory-derived factors on onset of MDD prevented us from drawing strong inferences on the evidence for the leading psychological theories.

- The influence of concurrent levels of baseline depressive symptoms on the prediction of MDD could not be ruled out, there was a potential publication bias and various ways to operationalise the theories across studies may have contributed to considerable heterogeneity.

the leading causes of disease burden. ${ }^{1}$ There are several preventative interventions and treatment options available for MDD (antidepressants and psychological interventions). ${ }^{23}$ However, their effectiveness raises concerns, with high relapse rates and approximately $50 \%$ of patients showing a clinical meaningful reduction in symptoms, or attaining full remission. ${ }^{4}$ Moreover, there is no indication that the effectiveness of current treatments for MDD improved over the past years. ${ }^{4}$ A recent meta-analysis found a significant decline since 1960 of the effectiveness of psychological interventions compared with control groups (including active control, waitlist control, usual care, or placebo or antidepressants) for MDD for youth. ${ }^{5}$ In addition, reported treatment effects may be overestimated due to publication bias and other 
biases (eg, bias due to treatment allocation, selective reporting of outcomes). ${ }^{36}$ The identification of factors that precede and increase the risk of the first onset of MDD might provide points to target with (preventive) interventions. Psychological factors believed to account for the onset of MDD generally originate from psychological models and theories. ${ }^{7}$ Up to now, a systematic review and meta-analysis of the empirical evidence for the leading psychological theories of the first onset of MDD is scarce.

Most current psychological interventions for prevention and treatment of MDD, for example, cognitive therapy (CT) ${ }^{89}$ behaviour activation (BA),${ }^{10}$ psychoanalytic therapy ${ }^{11}$ and interpersonal therapy (IPT), ${ }^{12}$ are derived from five psychological theories, which guided our systematic search (see online supplemental appendix A): behavioural, cognitive, psychodynamic, personalitybased and most theories include an overarching diathesis-stress perspective. ${ }^{13}$ The core principles of the five theories are briefly summarised below in reference to the corresponding psychological intervention.

Each theory postulates a hypothesis on specific factors that contribute to the aetiology of MDD. For example, cognitive theories emphasise the dominant role of cognitions in the development of MDD, and the way individuals view themselves, others and the world.$^{89}$ Negative cognitive processing across these domains is proposed to lead to an increased risk of MDD. The factors for the onset of MDD include higher levels of dysfunctional attitudes and beliefs, negative attributional style, rumination and learnt helplessness. ${ }^{914-20}$ CT (often combined with behavioural interventions) is an example of a cognitive theory-based intervention.

Originating from a framework of the learning theory, ${ }^{21}$ behavioural theories, that underlie treatments like BA, emphasise the role of the environment and the interaction between individuals and their environment in the development of MDD (eg, references ${ }^{22-28}$ ). It posited that decline of positive feedback prompts withdrawal behaviour (ie, low rate of response-contingent positive reinforcement) which further leads to depression. ${ }^{27} 29$ Examples of behavioural theory-derived factors are classical and operant conditioning, social skills or behaviours that lack potential reward-value such as withdrawal and inactivity. ${ }^{29}$

The psychodynamic theories were among the earliest to explain mental disorders including MDD, and have been used by clinicians and researchers to develop successive, overlapping models. ${ }^{30-38}$ Vulnerability factors derived from these theories include the mother-child relationship, object relations, quality of attachment with caregivers $^{35-38}$ and significant childhood experiences. ${ }^{30-35}$ Interventions derived from the psychodynamic theories (eg, psychoanalytic, psychodynamic and specific forms of IPT) often include a focus on attachment and interpersonal relationships. ${ }^{11}$

Another longstanding perspective, personality-based theories of MDD, has become an umbrella of multiple personality-based factors that may be related to the onset of MDD. The theories cover various taxonomies (traits/temperament) ${ }^{39}$ and hierarchy ('Big Five', 'Bo 'Big Three'). ${ }^{41}$ Among these, two major domains can be distilled: positive emotionality (PE) and negative emotionality (NE), with the assumption that depression-prone individuals experience heightened NE (eg, neuroticism) and reduced PE (eg, extraversion). ${ }^{42}$ Even though these four theories of MDD differ in the proposed vulnerability factors, the majority of these theories underscore the importance of stress in the development of MDD. Diathesis-stress theories underlying these theories propose that vulnerability factors (ie, the theory-derived vulnerability factors, 'diatheses') are activated by stress, or a combination of the vulnerability factor and stress, which leads to the development of MDD. ${ }^{43}$

Over the past decades, numerous studies and reviews have been conducted to delineate putative factors leading to the onset of MDD (eg, references ${ }^{42}{ }^{44-51}$ ) indicating that cognitive processes such as rumination and a dysfunctional thinking style ${ }^{48}$ and personality traits (eg, neuroticism) ${ }^{4252}$ increase the risk to develop MDD. Nevertheless, these reviews have not culminated in definitive evidence that supports etiological theories for onset of MDD. Support for the theories is largely based on crosssectional studies and/or studies that assessed MDD using self-reports instead of clinical interviews, or where relapse and onset were combined (eg, references ${ }^{48} 49$ ). Clinical interviews are needed to reliably establish whether there is indeed a first onset of MDD, as opposed to (subthreshold and/or self-reported) depressive symptomatology alone since self-report measures are not sufficient. To overcome these limitations, a systematic review of prospective, longitudinal, studies is needed among individuals without a history of MDD, where theory-derived factors are measured before the onset of MDD. This systematic review and meta-analysis investigate and summarise the evidence for factors derived from five leading theories of MDD that underpin most used treatment options.

\section{METHODS}

The methodology adopted in this meta-analysis and review was in line with the guidelines of Preferred Reporting Items for Systematic reviews and Meta-Analyses (PRISMA, online supplemental appendix B).

\section{Search strategies}

The current study was embedded in a larger project ('My optimism wears heavy boots', Netherlands Institute for Advanced Study) ${ }^{54}$ investigating the psychological and biological factors of MDD onset and relapse..$^{55}$ Therefore, some searches were combined over topics (see online supplemental appendix A). PubMed, PsycINFO, Cochrane and Embase were searched for relevant articles published from inception up to August 2019. The search combined keywords and text words relate to: first onset and studies with a prospective longitudinal design; MDD 
and five leading theories. Selection of the search terms indicative of the five psychological theories were guided by prior reviews, books and an extensive international expert panel (see acknowledgements for the expert panel). Snowballing was conducted by checking inclusions of previous published reviews and articles citing included studies.

\section{Inclusion and exclusion criteria}

Studies were eligible if the following criteria were fulfilled: (1) diagnostic status of MDD was indicated for all participants and was established through a clinical interview at follow-up (ie, Structured Clinical Interview for DSM (SCID), Schedule for Affective Disorders and Schizophrenia for School-Age Children (K-SADS) from DSM, CIDI from International Classification of Diseases (ICD)); (2) at baseline, participants did not meet criteria for MDD (and did not have depressive symptoms above cut-off scores for MDD), and did not have prior history of MDD; (3) participants with first-onset MDD had no comorbidity with other types of depressive disorder, other mental disorders or physical disease; (4) the study design was prospective/longitudinal; (5) the target variable(s) (theory-derived factors) were assessed before the first onset of MDD; participants needed to be assessed at least twice (baseline and follow-up) and (6) the study was original research, published in peer-reviewed journals in the English language. Studies with patients older than 65 years old were excluded because of the heterogeneity introduced by geriatric depression. When multiple publications with data from the same study cohort were available, we included the publication with longest period of follow-up length. When the follow-up period was equal, studies with largest number of total participants were included.

\section{Selection process}

The PRISMA flow diagram for all theories is depicted in figure 1. All records were screened by two screeners in an independent, but not fully blind way; the second screeners could see the decisions from the first screener. All eligible records that met the inclusion criteria during initial screening of the titles and abstracts were further assessed for eligibility by two screeners based on full

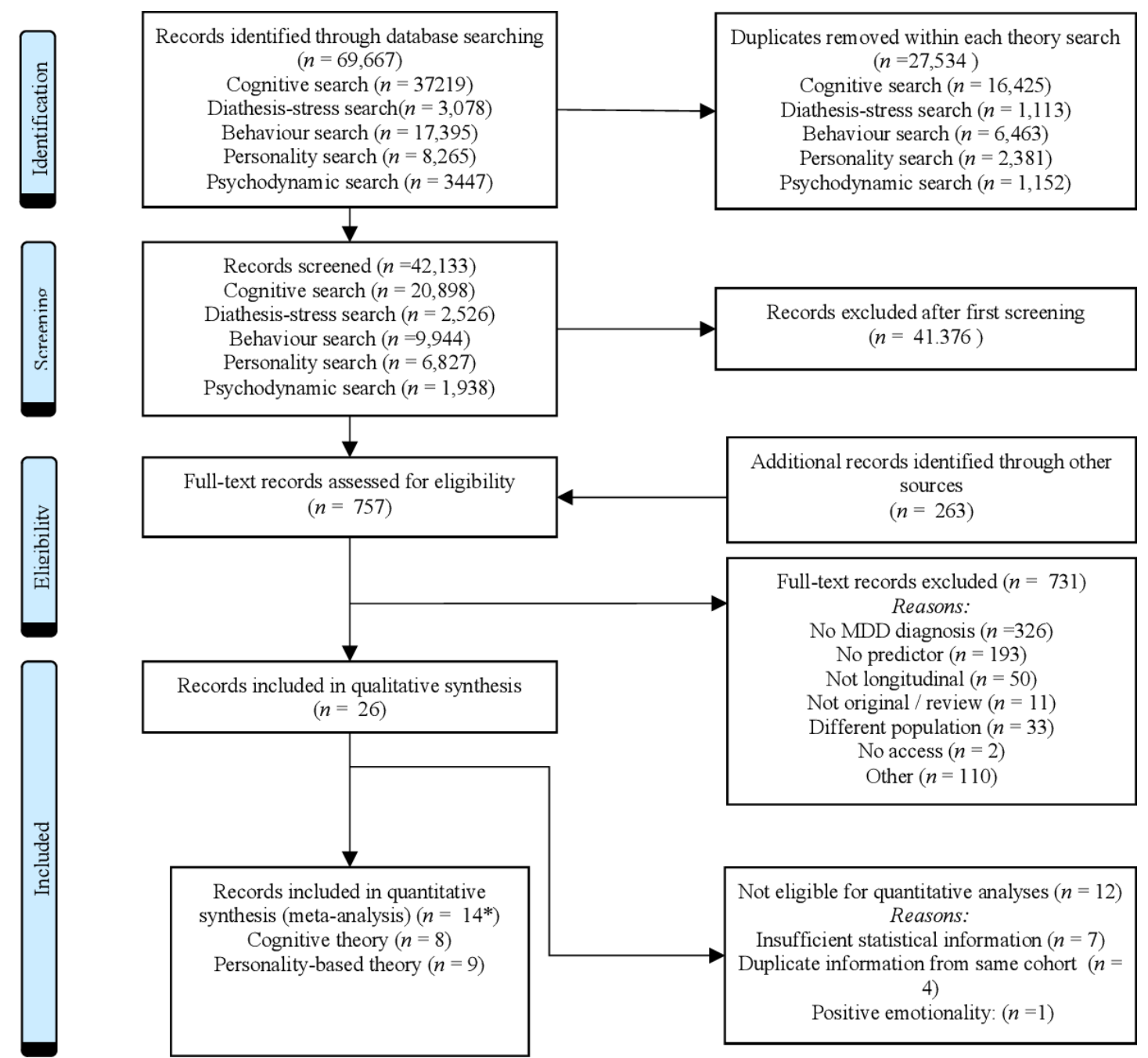

Figure 1 PRISMA flow diagram for the systematic review. *Studies can be included in both theories at same time. PRISMA, Preferred Reporting Items for Systematic reviews and Meta-Analyses; MDD, major depressive disorder 
texts. Any disagreement was resolved by discussion and consulting a senior author. Multiple screeners were included and assigned pairwise during this process, see author contributions and acknowledgements for the full list.

\section{Quality assessment and data extraction}

Two researchers assessed the risk of bias and level of confidence for the overall evidence for the psychological theories, using the criteria of the Grading of Recommendations Assessment, Development and Evaluation. ${ }^{57}$ Risk of bias was indicated in '+' (low risk of bias $=0$ ), '?' (unclear risk of bias $=1$ ) and '-' (high risk of bias $=2$ ). Score $0-6$, 6-12 and 12-18, indicated low, moderate and high risk of bias, respectively. We extracted demographic information, baseline depressive symptoms and its measurement scales, method of MDD diagnosis, psychological factors and statistical information to calculate the effect sizes. Authors were contacted when a study met the inclusion criteria, but reported insufficient data to calculate effect sizes. These authors were inquired via emails (a reminder was sent 2 weeks after if no response) on the possibility to provide the relevant statistics within 2 months. Studies were excluded in the meta-analysis if the necessary data were not provided within this timeframe.

\section{Primary outcome}

Primary outcome was the onset of MDD at study follow-up, as established by a clinical interview (eg, ICD, SCID) or expert opinion (eg, trained psychiatrist or clinical psychologist).

\section{Statistical analysis}

The programme Comprehensive Meta-Analysis (CMA V.3.3) ${ }^{58}$ was used to enter data of each study and each identified factor, and to calculate pooled effect sizes, forest plots, funnel plots and heterogeneity. The effect size of each factor reported in the article had to be expressed as an OR, risk ratio (RR) or HR, with $95 \%$ CIs, to indicate the relationship between the factor and time to, or odds or risk of having an onset of MDD at study follow-up. Alternatively, we calculated the OR, RR or HR by using reported statistics from each study and each factor. For example, the article needed to report means, SD, number of participants or beta coefficient with SE. These data were entered and OR, RR or HR with $95 \%$ CIs were then calculated using CMA. ${ }^{58}$ If more than one measure from the same main psychological theory was reported in the same study, a combined effect size was calculated in $\mathrm{CMA} .{ }^{58}$ If a study reported multiple factors derived from different theories, the effect sizes of these factors were allocated to the corresponding theory or theories.

We then calculated pooled effect sizes (HR, RR and OR) and its $95 \% \mathrm{CI}$ of each main theory separately using all (combined) factors assigned to that main theory. For example, the pooled effect size was calculated for all factors combined related to the cognitive theory (eg, dysfunctional attitudes, rumination, automatic thoughts). Since we expected considerable heterogeneity among studies and measures, a random effects model was employed to calculate pooled effect sizes. Second, separate subgroup analyses were conducted for each factor alone, if there were enough studies reporting that factor. To conduct these subgroup analyses, pooled effect sizes of each (theory-derived) factor were calculated using a mixed-effects model, with a random effects model to summarise the studies within each subgroup and a fixed effects model to test for differences between subgroups.

The $\mathrm{I}^{2}$ was calculated to assess heterogeneity between studies for each analysis. In general, heterogeneity is categorised at $0 \%-40 \%$ (low), 30\%-60\% (moderate), $50 \%-90 \%$ (substantial) and $75 \%-100 \%$ (considerable). ${ }^{59}$ The $95 \%$ CIs around $\mathrm{I}^{2}$ were calculated using the noncentral $\chi 2$-based approach within the Heterogi module for Stata. ${ }^{60}$ Funnel plots were visually inspected for publication bias, and investigated with Egger's test and Duval and Tweedie's trim and fill procedure. Trim-and-fill procedure was used to adjust potential publication bias. In this procedure, the asymmetric outlying studies in the funnel plot were first trimmed off and the true centre of the funnel was estimated with the symmetric remainders. Then, the funnel plot was filled with replacement of the trimmed studies and their missing counterparts around the centre. A newly pooled overall effect size based on this filled funnel plot indicated the OR after statistically adjusting the publication bias.

A priori, we aimed to conduct a meta-regression if the number of studies was sufficient, including investigating several potential continuous moderators of interest such as age, percentage female and baseline depressive symptoms were investigated. These variables were considered clinically relevant to major depression. ${ }^{61-63}$ Sensitivity analyses were conducted to examine if potential outliers, research designs and low-quality studies, affected the pooled effect sizes. The minimum number of studies was set at three studies for the main and subgroup analyses, and 10 for meta-regression.

\section{Patient and Public Involvement}

No patient involved.

\section{RESULTS}

Out of 69667 identified records (see figure 1), 42133 records were inspected on title/abstract after removal of duplicates, of which 52 articles met initial inclusion criteria across the psychological theories. For 26 of these articles (see online supplemental appendix $\mathrm{C}$ ), participants with prior MDD episodes were included and therefore those articles were excluded. In total, 26 articles were included in the final review. There were no eligible articles detected for the psychodynamic theories. A quantitative meta-analysis was only possible for the cognitive and personality-based theories. See table 1 for the characteristics of the included studies. 


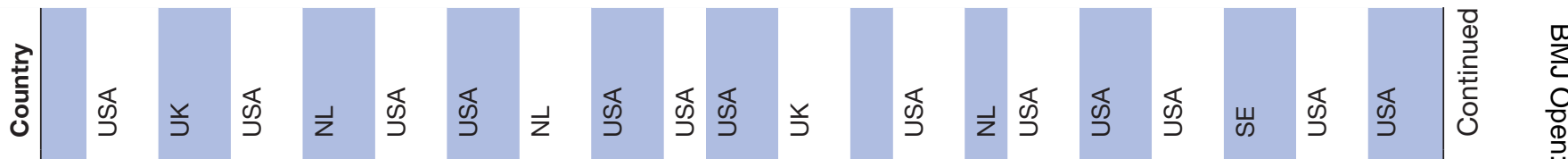

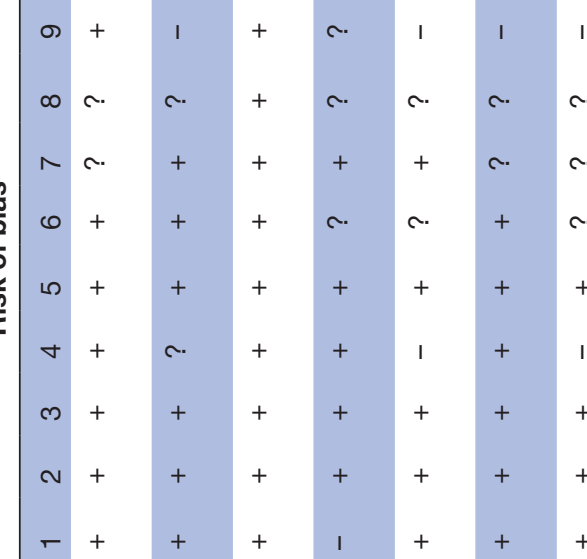

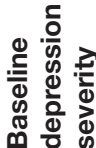

之

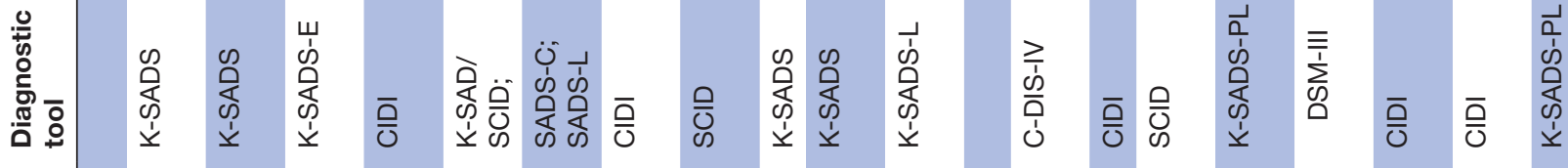

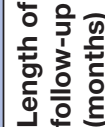

绩

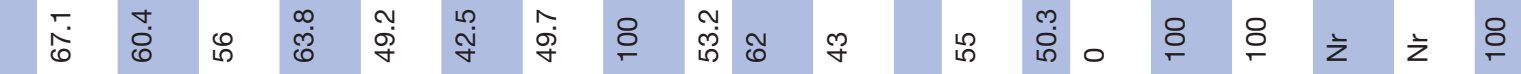

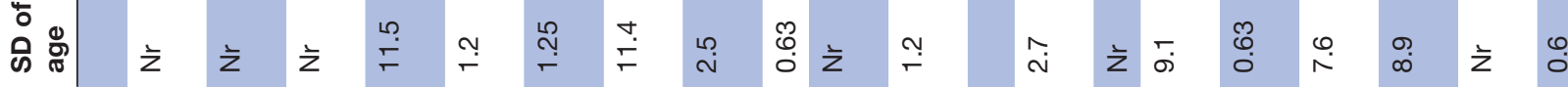

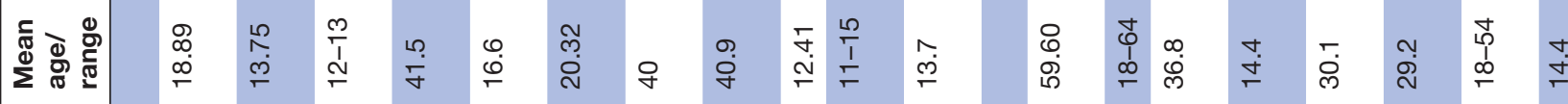

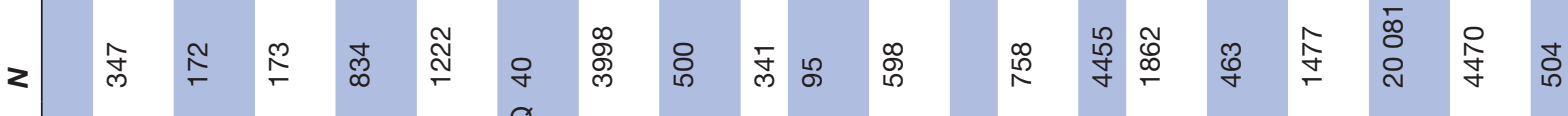

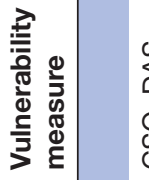

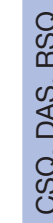

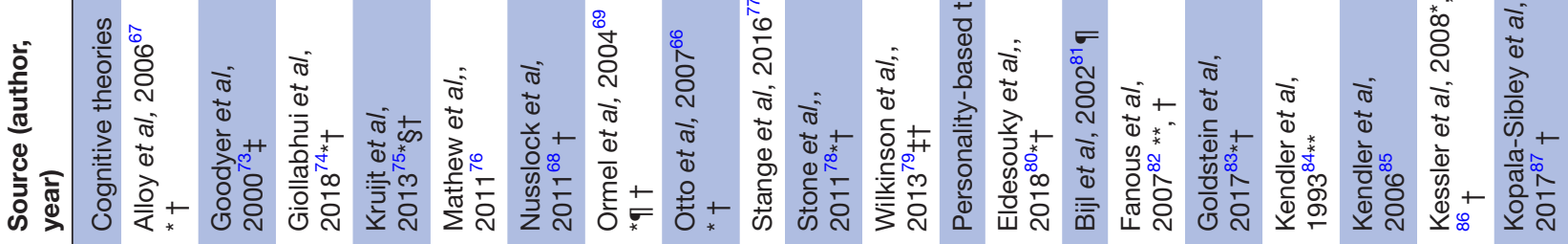

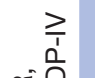

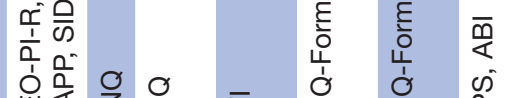

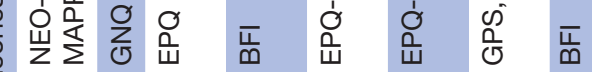




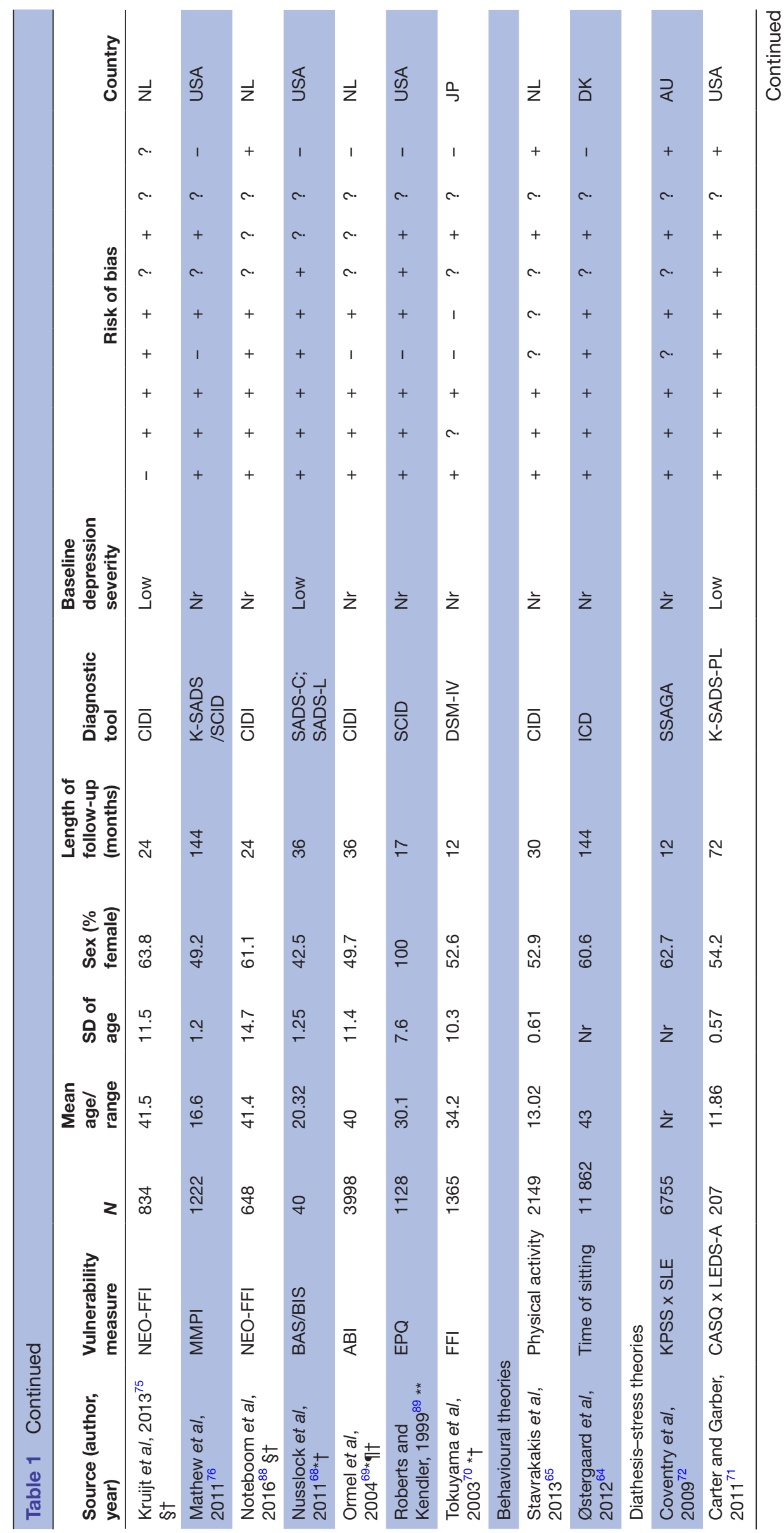

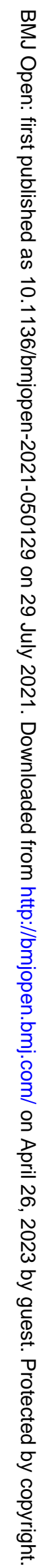




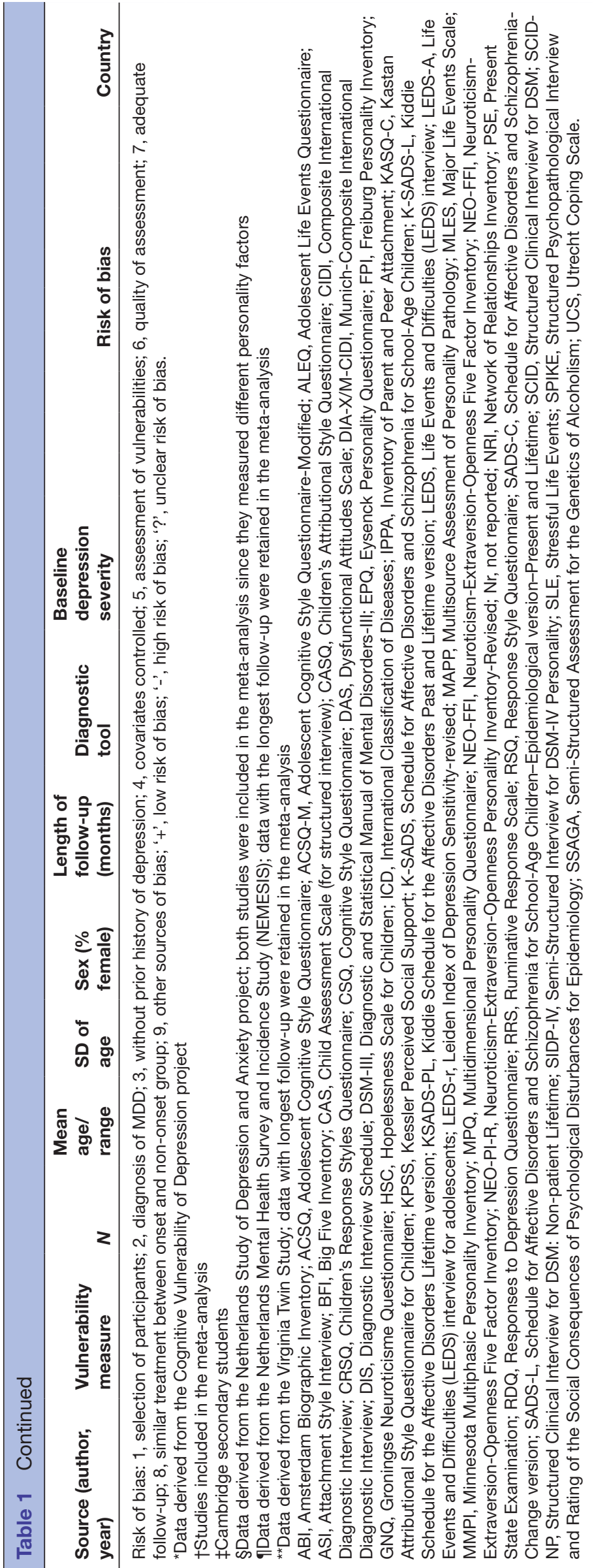


Cognitive theories

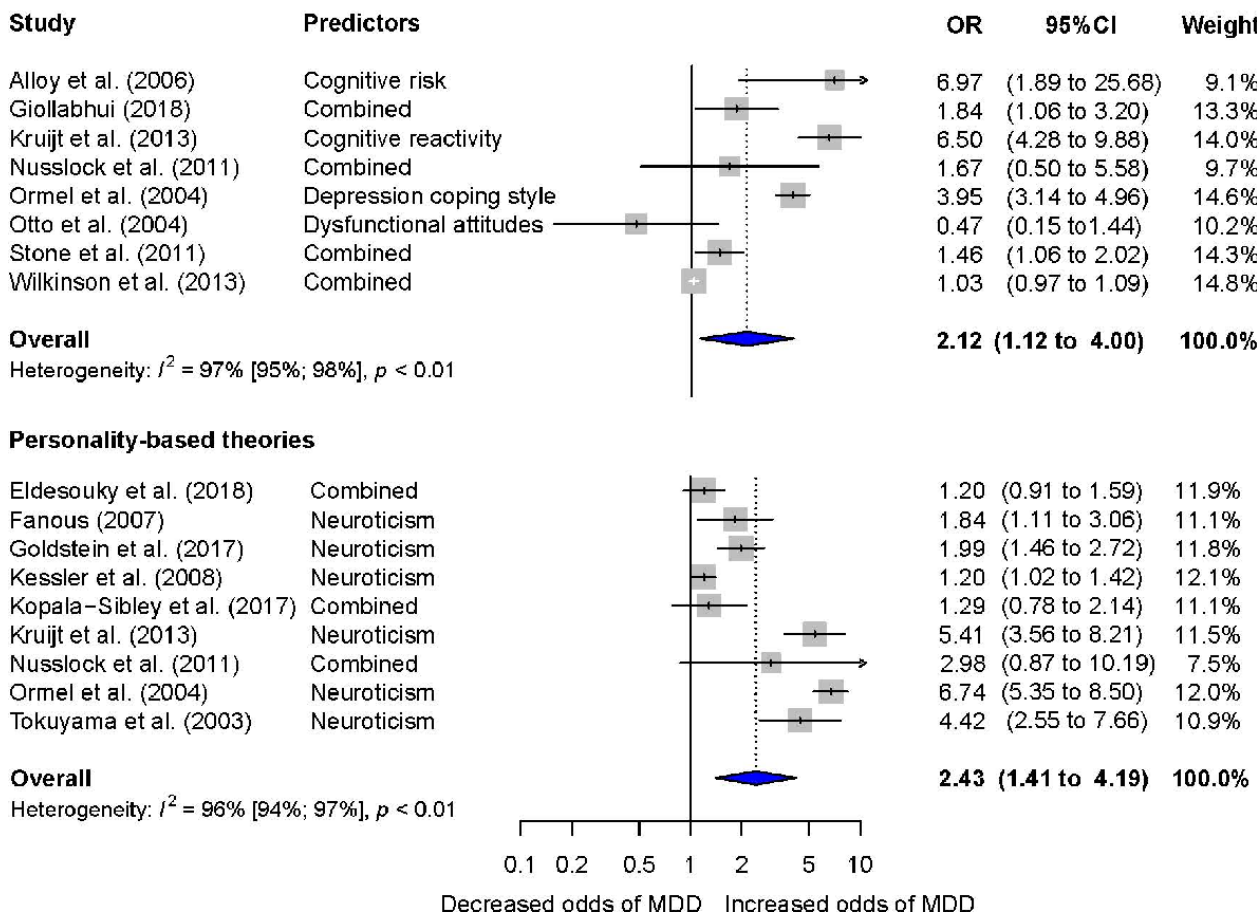

Figure 2 Forest plot of cognitive and personality-based theories to predict first onset of MDD. MDD, major depressive disorder.

\section{Behavioural theories}

Two studies were eligible for the behavioural theories ${ }^{64} 65$ and could not be meta-analysed. Both studies investigated the association between physical activities and onset of MDD, involving 14011 adolescents and adults. Low levels of physical activities were not associated with an increased risk of developing MDD.

\section{Cognitive theories}

Eleven studies were included (8320 participants), of which eight studies were eligible for the quantitative synthesis (6585 participants; $\mathrm{M}_{\text {age }}$ range $=13-41$; see figure 1). Follow-up time ranged from 1 to 12 years. The result of the overall analysis is shown in figure 2. The pooled $O R$ for the cognitive theory was $2.12(95 \%$ CI: 1.12 to 4.00 ), which indicates that the combination of cognitive theory-derived factors predicted the first onset of MDD. Heterogeneity was considerable $\left(\mathrm{I}^{2}=97 \%\right.$, 95\% CI: $95 \%$ to $98 \%$ ). Inspection of the funnel plot and Egger's test $(\mathrm{p}=0.12)$ did not indicate asymmetry; while Duval and Tweedie's trim and fill procedure (three studies trimmed) suggest potential publication bias. After statistically adjusting for publication bias, the overall $O R$ decreased to 1.11 with $95 \% \mathrm{CI}$ as 0.60 to 2.06 . The level of confidence was moderate. Given the low number of studies $(<10)$, no meta-regression analysis or subgroup analyses were conducted. Therefore, we were unable to examine potential moderators. The results remained comparable after removing one study with a moderate risk of bias $^{66}(O R=1.90,95 \%$ CI: 1.02 to 3.55$)$, however, were non-significant after conducting sensitivity analyses where one study with a different research design was removed (behaviour risk design $;{ }^{67} O R=1.88,95 \%$ CI: 0.97 to 3.94$)$. Two studies reported predictive value with one study controlling for baseline depressive symptom exclusively, and the other study controlling for other covariates concurrently. ${ }^{66}{ }^{68}$ We could therefore not investigate the impact of depressive symptoms on the meta-analysis.

\section{Personality-based theories Negative emotionality}

In total, 15 studies that investigated NE could be included in the qualitative synthesis (43 305 participants), of which nine studies were included in the quantitative analysis (14 394 participants, $M_{\text {age }}$ range=14-64). Follow-up length varied from 1 to 12 years. Eight of these nine studies investigated the role of neuroticism as a vulnerability factor; other factors were borderline personality and behaviour inhibition system. The pooled $O R$ for the NE was 2.43 (95\% CI: 1.41 to 4.19 ), indicating that NE was related to the first onset of MDD. See figure 2 for the overall results. Heterogeneity between studies was considerable $\left(\mathrm{I}^{2}=96 \%\right.$; $95 \%$ CI: $94 \%$ to $97 \%$ ), with a wide CI. The confidence of evidence was of high certainty. Inspection of the funnel plot and Egger's test $(p=0.52)$ did not indicate asymmetry, while trim and fill procedure indicated risk for publication bias with four trimmed studies resulted in an adjusted $O R$ as 1.39 (95\% CI: 0.74 to 2.59). Sensitivity analysis revealed similar decline after removal of two studies ${ }^{69} 70$ with moderate risk of bias $(O R=1.86 ; 95 \%$ CI: 1.25 to 2.78 ). The limited number of studies prohibited subgroup analyses and metaregression to investigate the effects of baseline depressive symptoms on the results. 


\section{Positive emotionality}

Six studies (8848 participants) focused on PE. The pooled $O R$ was 0.93 (95\% CI: 0.84 to 1.03 ), which indicates that positive personality traits did not decrease the odds of MDD onset. After removing one study with a high risk of bias, the effect remained non-significant $(O R=0.94$; 95\% CI: 0.85 to 1.05 ). Heterogeneity between studies was low ( $\mathrm{I}^{2}=37 \%$; $95 \%$ CI: $0 \%$ to $\left.75 \%\right)$. A publication bias was not indicated (Egger's test $\mathrm{p}=0.63$; number of trimmed studies $=0$ ).

\section{Diathesis-stress theories}

Two studies were identified that prospectively examined the interaction between theory-derived factors with stress on first onset of MDD, that is, diathesis-stress theories. ${ }^{712}$ Therefore, quantitative analyses were prohibited. The studies indicated non-significant results of social support ${ }^{69}$ and negative attributional style ${ }^{68}$ separately in interaction with stress, as predictors of MDD. No other studies included in the other theories combined the factors with measures of stress.

\section{DISCUSSION}

The aim was to systematically examine the evidence for psychological factors derived from five leading psychological theories that explain onset of MDD: behavioural, cognitive, personality-based, psychodynamic theories, including the diathesis-stress theory. Out of 42133 identified records, 26 studies examined theory-derived factors prospectively in participants without a history of MDD, of which 14 studies could be meta-analysed for the cognitive and personality-based theories. We identified no prospective studies on psychological factors such as attachment, object relations and identification, as mentioned in psychodynamic theories, and there were not enough studies for quantitative analyses of factors derived from the behavioural theory or diathesis-stress theory. Consistent with previous reviews, ${ }^{42}{ }^{48}$ individuals with higher levels of dysfunctional attitudes, rumination, and greater cognitive reactivity, as well as higher levels of the personality trait 'NE', had an increased odd to develop MDD. Therefore, there was some prospective evidence for the cognitive and personality-based theories of MDD.

This extensive systematic search enabled us to investigate prospectively assessed factors derived from five theories in clinically established MDD, while the lack of evidence overall remains noteworthy. Despite the strengths of this meta-analysis, that is, the inclusion of prospective, longitudinal studies that assessed the psychological factors before the first onset of MDD, and where MDD was established through clinical interviews, some limitations should be noted. The influence of concurrent levels of baseline depressive symptoms on the prediction of MDD cannot be ruled out due to the low number of studies reporting baseline symptomatology $(4 / 14)$. The marked heterogeneity that was observed may be attributed to low levels of consensus on operationalization of the theories, after consultation of lead experts in clinical psychology and psychiatry (see acknowledgements for details) to determine which factors belonged to which theories. Together with the potential publication bias, this can diminish the reliance of our result.

Despite these limitations, the present review takes an important first step to demonstrate the overall empirical status of five leading psychological theories that underpin widely used psychological interventions for MDD. The prospective evidence for the cognitive and personalitybased theories in relation to onset of MDD could assist researchers and clinicians to identify potential treatment targets and/or defined high-risk groups. As mentioned, cognitive theories $^{9}$ and personality theories ${ }^{42}$ as well as psychodynamic theories have an overlap with the diathesis-stress theory, yet there were not enough studies prospectively measuring stress or life events to investigate diathesis-stress theories. This precluded further examination of the influence of theory-derived factors under certain stressful situation. Overall, the limited number of eligible prospective studies on onset of MDD prevented us from drawing strong inferences.

The results highlight the lack of evidence of the factors derived from each theory in the onset of MDD. A research agenda should be formulated to systematically address these identified issues, including improved operationalization of leading theories, improved assessment of their factors and the use of prospective designs. All to ensure that interventions for depression are grounded in a solid foundation of clinical research. A framework that incorporates psychological, biological, environmental and social risk factors would provide a more integrative, holistic approach to unravel the underlying mechanisms of MDD.

\section{CONCLUSION}

There is some evidence that factors derived from cognitive and personality-based theories indeed predict the onset of MDD (ie, dysfunctional attitudes, cognitive styles, cognitive reactivity and NE). However, there were no studies that prospectively studied factors derived from psychodynamic theories and not enough studies to be able to examine the robust evidence for behavioural and diathesis-stress theories. More prospective and unified research is required to enable future systematic reviews. Overall, the prospective evidence for theory-derived psychological factors of MDD is limited.

Acknowledgements We would like to thank Dr H Burger for his advice and guidance, and the following student researchers for their assistance: F Moysidis, C Robertson, M Wauben, S Framson, M van Dalen, M Rennert, I Baltrusaityte, L Sun, C Song, Q Yu, WJ Li and B Yücel. Also, we would like to acknowledge the professional help from NIAS theme group (My optimism wears heavy boots: So much research, so few implications, towards 'patient-proof' empirical models and more effective interventions in mental health) from 1 February to 30 June in 2017. In specific, we would like to thank Dr A Cramer, Professor S Hollon, Professor J Ormel, Dr G Siegle, Professor P Spinhoven, Professor E Holmes, Professor C Harmer, Dr C Vinkers and Professor M van den Hout and the expert advisors Professor D Barlow, Dr H 
Boettcher, Dr S Dimidjian, Dr C Martell, Professor D Ekers and Dr L Gerritsen for their input and assistance in the project.

Contributors $\mathrm{CB}$ initiated the project. $\mathrm{CB}, \mathrm{MB}$ and $\mathrm{MK}$ set up the project, protocols and literature searches. ZF, MB, MK, AW and CB did the literature searches, extracted the data and selected the articles. $\mathrm{ZF}, \mathrm{AW}$ and $\mathrm{MB}$ entered the data. $\mathrm{ZF}$, $\mathrm{MB}, \mathrm{PC}$ and $\mathrm{CB}$ conducted the data analyses. ZF, CB, AW, MK, PC and MB wrote and revised the manuscript. $\mathrm{CB}$ and $\mathrm{MB}$ are the guarantors. The corresponding author attests that all listed authors meet authorship criteria and that no others meeting the criteria have been omitted.

Funding This study was partially supported by Netherlands Institute for Advanced Study in the Humanities and Social Sciences (NIAS), Grant awarded to Professor C Bockting ("My Optimism Wears Heavy Boots: So much research, so few implications, towards 'patient-proof' empirical models and more effective interventions in mental health") Royal Netherlands Academy of Arts and Sciences (KNAW).

Disclaimer The funding source had no role in the study design, collection, analysis or interpretation of the data, writing the manuscript or the decision to submit the paper for publication.

Competing interests None declared.

Patient consent for publication Not required.

Provenance and peer review Not commissioned; externally peer reviewed.

Data availability statement Data sharing not applicable as no data sets generated and/or analysed for this study. Data are available upon reasonable request. All data relevant to the study are included in the article or uploaded as supplementary information.

Supplemental material This content has been supplied by the author(s). It has not been vetted by BMJ Publishing Group Limited (BMJ) and may not have been peer-reviewed. Any opinions or recommendations discussed are solely those of the author(s) and are not endorsed by BMJ. BMJ disclaims all liability and responsibility arising from any reliance placed on the content. Where the content includes any translated material, BMJ does not warrant the accuracy and reliability of the translations (including but not limited to local regulations, clinical guidelines, terminology, drug names and drug dosages), and is not responsible for any error and/or omissions arising from translation and adaptation or otherwise.

Open access This is an open access article distributed in accordance with the Creative Commons Attribution Non Commercial (CC BY-NC 4.0) license, which permits others to distribute, remix, adapt, build upon this work non-commercially, and license their derivative works on different terms, provided the original work is properly cited, appropriate credit is given, any changes made indicated, and the use is non-commercial. See: http://creativecommons.org/licenses/by-nc/4.0/.

\section{ORCID iDs}

Marlies Brouwer http://orcid.org/0000-0002-9972-9058

Pim Cuijpers http://orcid.org/0000-0001-5497-2743

\section{REFERENCES}

1 Ferrari AJ, Charlson FJ, Norman RE, et al. Burden of depressive disorders by country, sex, age, and year: findings from the global burden of disease study 2010. PLoS Med 2013;10:e1001547.

2 Breedvelt JJF, Kandola A, Kousoulis AA, et al. What are the effects of preventative interventions on major depressive disorder (MDD) in young adults? A systematic review and meta-analysis of randomized controlled trials. J Affect Disord 2018;239:18-29.

3 Cuijpers P, Karyotaki E, Reijnders M, et al. Was Eysenck right after all? A reassessment of the effects of psychotherapy for adult depression. Epidemiol Psychiatr Sci 2019;28:21-30.

4 Holmes EA, Craske MG, Graybiel AM. Psychological treatments: a call for mental-health science. Nature 2014;511:287-9.

5 Weisz JR, Kuppens S, Ng MY, et al. Are psychotherapies for young people growing stronger? tracking trends over time for youth anxiety, depression, attention-deficit/hyperactivity disorder, and conduct problems. Perspect Psychol Sci 2019;14:216-37.

6 Driessen E, Hollon SD, Bockting CLH, et al. Does publication bias Inflate the apparent efficacy of psychological treatment for major depressive disorder? A systematic review and meta-analysis of US National Institutes of Health-Funded trials. PLoS One 2015;10:e0137864.

7 Cuijpers P. Preventing the onset of depressive disorders an overview. Public Heal Perspect Depress Disord 2017:411-30.
8 Beck AT, Rush AJ, Shaw BF. Cognitive therapy of depression. New York City, NY, US: The Guilford Press, 1979.

9 Beck AT. A unified model of depression: integrating clinical, cognitive, biological, and evolutionary perspectives. Clin Psychol Sci 2016;4:596-619.

10 Dimidjian S, Barrera M, Martell C, et al. The origins and current status of behavioral activation treatments for depression. Annu Rev Clin Psychol 2011;7:1-38.

11 Luyten P, Blatt SJ. Psychodynamic treatment of depression. Psychiatr Clin North Am 2012;35:111-29.

12 Cuijpers P, Geraedts AS, van Oppen P, et al. Interpersonal psychotherapy for depression: a meta-analysis. Am J Psychiatry 2011;168:581-92.

13 Fernald D. Psychology: six perspectives. California: SAGE Publications, Inc, 2008.

14 Abramson LY, Metalsky GI, Alloy LB. Hopelessness depression: a theory-based subtype of depression. Psychol Rev 1989;96:358-72.

15 Abramson LY, Seligman ME, Teasdale JD. Learned helplessness in humans: critique and reformulation. J Abnorm Psychol 1978;87:49-74.

16 Dozois DJA, Rnic K. Core beliefs and self-schematic structure in depression. Curr Opin Psychol 2015;4:98-103.

17 Gotlib IH, Joormann J, Cognition JJ. Cognition and depression: current status and future directions. Annu Rev Clin Psychol 2010;6:285-312.

18 Hawke LD, Provencher MD. Schema theory and schema therapy in mood and anxiety disorders: a review. J Cogn Psychother 2011;25:257-76.

19 Kircanski K, Joormann J, Gotlib IH. Cognitive aspects of depression. Guilford Press, 2012: 3. 301-13.

20 Nolen-Hoeksema S. Responses to depression and their effects on the duration of depressive episodes. J Abnorm Psychol 1991;100:569-82.

21 Skinner BF. Verbal behaviour. New York: Copley Publishing Group, $1957 .$.

22 Costello CG. Depression: loss of reinforcers of loss of reinforcer effectiveness? Behav Ther 1972;3:240-7.

23 Coyne JC. Depression and the response of others. J Abnorm Psychol 1976;85:186.

24 Ferster CB. Behavioral approaches to depression. In: The psychology of depression: contemporary theory and research. Oxford, England: John Wiley \& Sons;

25 Lazarus AA. Some reactions to Costello's paper on depression. Behav Ther 1972;3:248-50.

26 Lejuez CW, Hopko DR, Hopko SD, LePage JP. A brief behavioral activation treatment for depression. treatment manual. Behav Modif 2001;25:164-75.

27 Lewinsohn P, Youngren M, Grosscup S. Reinforcement and depression. Psychobiol Depress Disord Implic Eff Stress 1979:291-316.

28 Nezu AM. A problem-solving formulation of depression: a literature review and proposal of a pluralistic model. Clin Psychol Rev 1987; $7: 121-44$

29 Lewinsohn P. The Behavioral Study and Treatment of Depression. In: Progress in behavior modification. Elsevier, 1975: 19-64.

30 Sandler J, Joffe WG. Notes on childhood depression. Int J Psychoanal 1965;46:88-96.

31 Kohut H. The analysis of the self. New York: Int, 1971.

32 Jacobson E. The psychoanalytic treatment of depressive patients. Depress Hum Exist Bost Little, Brown 1975:431-43.

33 Stone L. Psychoanalytic observations on the pathology of depressive illness: selected spheres of ambiguity or disagreement. J Am Psychoanal Assoc 1986;34:329-62 http://www.embase.com/search/ results?subaction=viewrecord\&from=export\&id=L16086963

34 Mackinnon A, Henderson AS, Andrews G. Parental 'affectionless control' as an antecedent to adult depression: a risk factor refined. Psychol Med 1993;23:135-41.

35 Freud S. Mourning and melancholia. Essent Pap object loss, 1994. Available: http://ovidsp.ovid.com/ovidweb.cgi?T=JS\&PAGE= reference $\& \mathrm{D}=$ psyc3\&NEWS $=\mathrm{N} \& A N=1994-97593-003$

36 Bibring E. The mechanism of depression. In: Affective disorders: Psychoanalytic contributions to their study. Oxford, England: International Universities Press, 1953.

37 Blatt SJ, Homann E. Parent-Child interaction in the etiology of dependent and self-critical depression. Clin Psychol Rev 1992;12:47-91 http://ovidsp.ovid.com/ovidweb.cgi?T=JS\&PAGE= reference\&D=psyc3\&NEWS $=\mathrm{N} \& A N=1992-23621-001$

38 Bowlby J. A secure base: clinical applications of attachment theory. Routledge, 1988.

39 Clark LA, Watson D. Temperament: a new paradigm for trait psychology. Handb Personal Theory Res 1999;2:399-423. 
40 Goldberg LR. An alternative "Description of personality": The big-five factor structure. Sci Ment Heal 2013;59:34-48.

41 Markon KE, Krueger RF, Watson D. Delineating the structure of normal and abnormal personality: an integrative hierarchical approach. J Pers Soc Psychol 2005;88:139-57.

42 Klein DN, Kotov R, Bufferd SJ, Personality BSJ. Personality and depression: explanatory models and review of the evidence. Annu Rev Clin Psychol 2011;7:269-95.

43 Hankin BL, Abela JRZ. Development of psychopathology: a Vulnerability-Stress perspective. Thousand Oaks, California: SAGE Publications, 2005.

44 Bagby RM, Psych C, Quilty LC, Ryder AC, et al. Personality and depression. Can J Psychiatry 2008;53:14-25.

45 Beatson J, Taryan S. Predisposition to depression: the role of attachment. Aust N Z J Psychiatry 2003;37:219-25.

46 Enns MW, Cox BJ. Personality dimensions and depression: review and commentary. Can J Psychiatry 1997;42:274-84.

47 Haaga DA, Dyck MJ, Ernst D. Empirical status of cognitive theory of depression. Psychol Bull 1991;110:215-36.

48 Lakdawalla Z, Hankin BL, Mermelstein R. Cognitive theories of depression in children and adolescents: a conceptual and quantitative review. Clin Child Fam Psychol Rev 2007;10:1-24.

49 Lewinsohn PM, Allen NB, Seeley JR, et al. First onset versus recurrence of depression: differential processes of psychosocial risk. $J$ Abnorm Psychol 1999;108:483-9.

50 Mathews A, MacLeod C. Cognitive vulnerability to emotional disorders. Annu Rev Clin Psychol 2005;1:167-95.

51 Miranda J. Dysfunctional thinking is activated by stressful life events. Cognit Ther Res 1992;16:473-83.

52 Ormel J, Jeronimus BF, Kotov R, et al. Neuroticism and common mental disorders: meaning and utility of a complex relationship. Clin Psychol Rev 2013;33:686-97.

53 Hong RY, Cheung M. The structure of cognitive vulnerabilities to depression and anxiety: evidence for a common core etiologic process based on a meta-analytic review. Clin Psychol Sci 2015;3:892-912.

54 Bockting CLH, Hollon SD, Siegle G, et al. My optimism wears heavy boots: so much research, so few implications, towards "patientproof" empirical models and more effective interventions in mental health.

55 Brouwer ME, Williams AD, Kennis M, et al. Psychological theories of depressive relapse and recurrence: a systematic review and metaanalysis of prospective studies. Clin Psychol Rev 2019;74:101773.

56 Kennis M, Gerritsen L, van Dalen M, et al. Prospective biomarkers of major depressive disorder: a systematic review and meta-analysis. Mol Psychiatry 2020;25:1-18

57 Langer G, Meerpohl JJ, Perleth M, et al. [GRADE guidelines: 1. Introduction - GRADE evidence profiles and summary of findings tables]. Z Evid Fortbild Qual Gesundhwes 2012;106:357-68.

58 Borenstein M, Hedges L V, Higgins JPT, et al. Comprehensive metaanalysis (CMA) software. version 3.0, 2014.

59 Chandler J, Cumpston M, Li T. Cochrane Handbook for systematic reviews of interventions. John Wiley \& Sons, 2019.

60 Orsini N, Bottai M, Higgins J. Heterogi: Stata module to quantify heterogeneity in a meta-analysis. Stat Softw Components 2006.

61 Cuijpers P, Smit F. Subthreshold depression as a risk indicator for major depressive disorder: a systematic review of prospective studies. Acta Psychiatr Scand 2004;109:325-31.

62 Stordal E, Mykletun A, Dahl AA. The association between age and depression in the general population: a multivariate examination. Acta Psychiatr Scand 2003;107:132-41.

63 Salk RH, Hyde JS, Abramson LY. Gender differences in depression in representative national samples: meta-analyses of diagnoses and symptoms. Psychol Bull 2017;143:783-822.

64 Østergaard D, Dalton SO, Bidstrup PE, et al. Mental vulnerability as a risk factor for depression: a prospective cohort study in Denmark. Int J Soc Psychiatry 2012;58:306-14.

65 Stavrakakis N, Roest AM, Verhulst F, et al. Physical activity and onset of depression in adolescents: a prospective study in the general population cohort trails. J Psychiatr Res 2013;47:1304-8.

66 Otto MW, Teachman BA, Cohen LS, et al. Dysfunctional attitudes and episodes of major depression: predictive validity and temporal stability in never-depressed, depressed, and recovered women. $J$ Abnorm Psychol 2007:116:475-83.

67 Alloy LB, Abramson LY, Whitehouse WG, et al. Prospective incidence of first onsets and recurrences of depression in individuals at high and low cognitive risk for depression. $J$ Abnorm Psychol 2006:115:145-56.
68 Nusslock R, Shackman AJ, Harmon-Jones E, et al. Cognitive vulnerability and frontal brain asymmetry: common predictors of first prospective depressive episode. J Abnorm Psychol 2011;120:497-503.

69 Ormel J, Oldehinkel AJ, Vollebergh W. Vulnerability before, during, and after a major depressive episode: a 3-wave population-based study. Arch Gen Psychiatry 2004;61:990-6.

70 Tokuyama M, Nakao K, Seto M, et al. Predictors of first-onset major depressive episodes among white-collar workers. Psychiatry Clin Neurosci 2003:57:523-31.

71 Carter JS, Garber J. Predictors of the first onset of a major depressive episode and changes in depressive symptoms across adolescence: stress and negative cognitions. J Abnorm Psychol 2011;120:779-96.

72 Coventry WL, Medland SE, Wray NR, et al. Phenotypic and discordant-monozygotic analyses of stress and perceived social support as antecedents to or sequelae of risk for depression. Twin Res Hum Genet 2009;12:469-88.

73 Goodyer IM, Herbert J, Tamplin A, et al. First-episode major depression in adolescents. affective, cognitive and endocrine characteristics of risk status and predictors of onset. $\mathrm{Br} J$ Psychiatry 2000;176:142-51.

74 Mac Giollabhui N, Hamilton JL, Nielsen J, et al. Negative cognitive style interacts with negative life events to predict first onset of a major depressive episode in adolescence via hopelessness. $J$ Abnorm Psychol 2018;127:1-11.

75 Kruijt A-W, Antypa N, Booij L, et al. Cognitive reactivity, implicit associations, and the incidence of depression: a two-year prospective study. PLoS One 2013;8:e70245

76 Mathew AR, Pettit JW, Lewinsohn PM, et al. Co-Morbidity between major depressive disorder and anxiety disorders: shared etiology or direct causation? Psychol Med 2011;41:2023-34.

77 Stange JP, Connolly SL, Burke TA, et al. INFLEXIBLE cognition predicts first onset of major depressive episodes in adolescence. Depress Anxiety 2016;33:1005-12.

78 Stone LB, Hankin BL, Gibb BE, et al. Co-rumination predicts the onset of depressive disorders during adolescence. J Abnorm Psychol 2011;120:752-7.

79 Wilkinson PO, Croudace TJ, Goodyer IM. Rumination, anxiety, depressive symptoms and subsequent depression in adolescents at risk for psychopathology: a longitudinal cohort study. BMC Psychiatry 2013:13:250.

80 Eldesouky L, Thompson RJ, Oltmanns TF, et al. Affective instability predicts the course of depression in late middle-age and older adulthood. J Affect Disord 2018;239:72-8.

81 Bijl RV, De Graaf R, Ravelli A, et al. Gender and age-specific first incidence of DSM-III-R psychiatric disorders in the general population. results from the Netherlands mental health survey and incidence study (nemesis). Soc Psychiatry Psychiatr Epidemiol 2002;37:372-81.

82 Fanous $\mathrm{AH}$, Neale MC, Aggen $\mathrm{SH}$, et al. A longitudinal study of personality and major depression in a population-based sample of male twins. Psychol Med 2007;37:1163-72.

83 Goldstein BL, Kotov R, Perlman G, et al. Trait and facet-level predictors of first-onset depressive and anxiety disorders in a community sample of adolescent girls. Psychol Med 2018;48:1282-90.

84 Kendler KS, Neale MC, Kessler RC, et al. A longitudinal twin study of personality and major depression in women. Arch Gen Psychiatry 1993:50:853-62.

85 Kendler KS, Gatz M, Gardner CO, et al. Personality and major depression: a Swedish longitudinal, population-based twin study. Arch Gen Psychiatry 2006;63:1113-20.

86 Kessler RC, Gruber M, Hettema JM, et al. Co-Morbid major depression and generalized anxiety disorders in the National comorbidity survey follow-up. Psychol Med 2008;38:365-74.

87 Kopala-Sibley DC, Klein DN, Perlman G, et al. Self-criticism and dependency in female adolescents: prediction of first onsets and disentangling the relationships between personality, stressful life events, and internalizing psychopathology. J Abnorm Psychol 2017;126:1029-43

88 Noteboom A, Beekman ATF, Vogelzangs N, et al. Personality and social support as predictors of first and recurrent episodes of depression. J Affect Disord 2016;190:156-61.

89 Roberts SB, Kendler KS. Neuroticism and self-esteem as indices of the vulnerability to major depression in women. Psychol Med 1999;29:1101-9. 